\title{
Automated Identification of Molecular Crystal's Packing Motifs
}

\author{
Supplementary Information
}

Donald Loveland $^{1}$, Bhavya Kailkhura ${ }^{2}$, Piyush Karande ${ }^{3}$, Anna M. Hiszpanski ${ }^{1 *}$, and T. Yong-Jin $\operatorname{Han}^{1 *}$

${ }^{1}$ Materials Science Division, Lawrence Livermore National Laboratory, Livermore, CA 94550

${ }^{2}$ Center for Applied Scientific Computing, Lawrence Livermore National Laboratory, Livermore, CA 94550

${ }^{3}$ Computational Engineering Division, Lawrence Livermore National Laboratory, Livermore, CA 94550

\section{Corresponding Author}

* hiszpanski2@1lnl.gov

*han5@llnl.gov

\section{EVALUATION AND LABELING}

\section{Evaluation dataset}

In order to evaluate the different labeling methods, a set of 172 molecular crystals were hand-labeled by SMEs. This dataset is enumerated in Table 1 with the associated predicted packing motifs and packing motif labels. The dataset is composed of 135 randomly chosen PAHs and energetic-like molecules from CCDC as well as 37 energetic-like molecules from a recent review article, which is designated by the source dataset column. If a refcode's autopack predicted motifs and human labeled motifs values are N/A, the crystal structure could not be labeled due to factors described in the Algorithm comparison section of the main text. On rare occasions, CCDC produces a CIF file with either corrupt or missing information, meaning it is impossible to properly construct the associated crystal structure. Those cases are also denoted by an N/A.

Table S1. Packing Motif Dataset

\begin{tabular}{llll}
\hline RefCode & Source & Autopack Predicted Motifs & Human Labeled Motifs \\
\hline AANHOX01 & HE - PAH & Herringbone & Herringbone \\
\hline AARBOX & HE - PAH & N/A & N/A \\
\hline ABAGIV & HE - PAH & Gamma & Gamma \\
\hline ABAHIW & HE - PAH & Beta & Beta \\
\hline ABANAU & HE - PAH & N/A & N/A \\
\hline ABAPIE & HE - PAH & N/A & N/A \\
\hline ABATUU & HE - PAH & N/A \\
\hline ABAVAC & HE - PAH $/ A$ & Gamma \\
\hline ABAVEG & HE - PAH & Gamma & Beta \\
\hline ABAVUW & HE - PAH & Beta & Herringbone \\
\hline ABAWEH & HE - PAH & Herringbone & N/A \\
\hline ABECAL & HE - PAH & N/A & Herringbone \\
\hline ABEJOH & HE - PAH & Gamma & Herringbone \\
\hline ABEKUO & HE - PAH & Gamma & Gamma \\
\hline ABELID & HE - PAH & Gamma & N/A \\
\hline ABENAX & HE - PAH & N/A & Beta \\
\hline ABENUQ & HE - PAH & Beta & Beta \\
\hline ABEPON & HE - PAH & Beta & N/A \\
\hline ABEQIK & HE - PAH & N/A & N/A \\
\hline
\end{tabular}




\begin{tabular}{|c|c|c|c|}
\hline ABICUJ & $\mathrm{HE}$ - PAH & Beta & Beta \\
\hline ABIFUO & $\mathrm{HE}$ - PAH & Sandwich Herringbone & Sandwich Herringbone \\
\hline ABIGUQ & $\mathrm{HE}-\mathrm{PAH}$ & Herringbone & Gamma \\
\hline ABIHAX & $\mathrm{HE}$ - PAH & Beta & Beta \\
\hline ABOFIH & $\mathrm{HE}-\mathrm{PAH}$ & N/A & N/A \\
\hline ABORIS & $\mathrm{HE}-\mathrm{PAH}$ & Beta & Beta \\
\hline ABULIT & $\mathrm{HE}$ - PAH & Gamma & Sandwich Herringbone \\
\hline ANTCEN & $\mathrm{HE}-\mathrm{PAH}$ & Herringbone & Herringbone \\
\hline AVUZIB & $\mathrm{HE}$ - PAH & Gamma & Gamma \\
\hline BALYAR & $\mathrm{HE}-\mathrm{PAH}$ & Gamma & Gamma \\
\hline BANHOO & $\mathrm{HE}-\mathrm{PAH}$ & Beta & Beta \\
\hline BANHOO01 & $\mathrm{HE}-\mathrm{PAH}$ & Gamma & Gamma \\
\hline BANHOOO2 & $\mathrm{HE}-\mathrm{PAH}$ & Gamma & Gamma \\
\hline BANHOOO3 & $\mathrm{HE}$ - PAH & Beta & Beta \\
\hline BEANTR & $\mathrm{HE}-\mathrm{PAH}$ & Herringbone & Herringbone \\
\hline BIRDEL & $\mathrm{HE}$ - PAH & Sandwich Herringbone & Sandwich Herringbone \\
\hline BNPERY & $\mathrm{HE}-\mathrm{PAH}$ & Sandwich Herringbone & Sandwich Herringbone \\
\hline BNPYRE10 & $\mathrm{HE}$ - PAH & Gamma & Gamma \\
\hline BODMAI & $\mathrm{HE}-\mathrm{PAH}$ & Gamma & Gamma \\
\hline BOXGAW & $\mathrm{HE}$ - PAH & Gamma & Gamma \\
\hline BZPHAN & $\mathrm{HE}-\mathrm{PAH}$ & Gamma & Gamma \\
\hline CENXUO & $\mathrm{HE}-\mathrm{PAH}$ & N/A & N/A \\
\hline CENYAV & $\mathrm{HE}$ - PAH & N/A & N/A \\
\hline CENYEZ & $\mathrm{HE}-\mathrm{PAH}$ & N/A & N/A \\
\hline CEQGEL & $\mathrm{HE}-\mathrm{PAH}$ & Sandwich Herringbone & Sandwich Herringbone \\
\hline CIWMAW01 & $\mathrm{HE}-\mathrm{PAH}$ & Beta & Beta \\
\hline CIZPIK & $\mathrm{HE}$ - PAH & Gamma & Gamma \\
\hline CORONE & $\mathrm{HE}-\mathrm{PAH}$ & Gamma & Gamma \\
\hline CORONE01 & $\mathrm{HE}-\mathrm{PAH}$ & Gamma & Gamma \\
\hline CRYSEN & $\mathrm{HE}-\mathrm{PAH}$ & Herringbone & Herringbone \\
\hline CRYSEN01 & $\mathrm{HE}-\mathrm{PAH}$ & Herringbone & Herringbone \\
\hline DATNBZ & $\mathrm{HE}$ - PAH & Gamma & Gamma \\
\hline DBNTHRO2 & $\mathrm{HE}-\mathrm{PAH}$ & Herringbone & Herringbone \\
\hline DBPERY & $\mathrm{HE}$ - PAH & Gamma & Gamma \\
\hline DBPHENO2 & $\mathrm{HE}-\mathrm{PAH}$ & Gamma & Herringbone \\
\hline DBZCOR & $\mathrm{HE}-\mathrm{PAH}$ & Gamma & Gamma \\
\hline DNAPAN & $\mathrm{HE}$ - PAH & Sandwich Herringbone & Sandwich Herringbone \\
\hline DPANTR01 & $\mathrm{HE}$ - PAH & Herringbone & Herringbone \\
\hline DUPHAX & $\mathrm{HE}-\mathrm{PAH}$ & Gamma & Gamma \\
\hline HBZCOR & $\mathrm{HE}-\mathrm{PAH}$ & Gamma & Gamma \\
\hline HBZCOR01 & $\mathrm{HE}-\mathrm{PAH}$ & Gamma & Gamma \\
\hline IZUCIP & $\mathrm{HE}-\mathrm{PAH}$ & Sandwich Herringbone & Sandwich Herringbone \\
\hline JULSOY & $\mathrm{HE}$ - PAH & Beta & Beta \\
\hline KAFVUI & $\mathrm{HE}-\mathrm{PAH}$ & Gamma & Gamma \\
\hline KAGFOP & $\mathrm{HE}$ - PAH & Gamma & Herringbone \\
\hline KAGFUV & $\mathrm{HE}-\mathrm{PAH}$ & Gamma & Gamma \\
\hline KAGGEG & $\mathrm{HE}-\mathrm{PAH}$ & Gamma & Herringbone \\
\hline KANQAR & $\mathrm{HE}-\mathrm{PAH}$ & Beta & Beta \\
\hline KEKULN10 & $\mathrm{HE}-\mathrm{PAH}$ & Gamma & Gamma \\
\hline KUBWAF01 & $\mathrm{HE}$ - PAH & N/A & N/A \\
\hline MAYXOZ & $\mathrm{HE}-\mathrm{PAH}$ & Sandwich Herringbone & Herringbone \\
\hline MEXTUG & $\mathrm{HE}$ - PAH & Beta & Beta \\
\hline MIKTIK & $\mathrm{HE}-\mathrm{PAH}$ & Gamma & Sandwich Herringbone \\
\hline
\end{tabular}




\begin{tabular}{|c|c|c|c|}
\hline NAPANT01 & $\mathrm{HE}-\mathrm{PAH}$ & Beta & Beta \\
\hline NETKII & $\mathrm{HE}-\mathrm{PAH}$ & Gamma & Gamma \\
\hline OVALEN01 & $\mathrm{HE}-\mathrm{PAH}$ & Gamma & Gamma \\
\hline PENCEN & $\mathrm{HE}-\mathrm{PAH}$ & Herringbone & Herringbone \\
\hline PERLEN01 & $\mathrm{HE}-\mathrm{PAH}$ & Sandwich Herringbone & Sandwich Herringbone \\
\hline PEZPIU & $\mathrm{HE}-\mathrm{PAH}$ & Gamma & Herringbone \\
\hline PHENAN08 & $\mathrm{HE}$ - PAH & Herringbone & Herringbone \\
\hline PHENAN13 & $\mathrm{HE}-\mathrm{PAH}$ & Herringbone & Herringbone \\
\hline PHNAPH & $\mathrm{HE}$ - PAH & Gamma & Gamma \\
\hline POBPIG & $\mathrm{HE}-\mathrm{PAH}$ & Sandwich Herringbone & Herringbone \\
\hline POMWOE & $\mathrm{HE}-\mathrm{PAH}$ & Gamma & Gamma \\
\hline PUJQIV & $\mathrm{HE}-\mathrm{PAH}$ & Herringbone & Herringbone \\
\hline PYRENE02 & $\mathrm{HE}-\mathrm{PAH}$ & Sandwich Herringbone & Sandwich Herringbone \\
\hline PYRPYR10 & $\mathrm{HE}$ - PAH & Beta & Beta \\
\hline QEDHEP & $\mathrm{HE}-\mathrm{PAH}$ & Gamma & Gamma \\
\hline QQQCIG11 & $\mathrm{HE}-\mathrm{PAH}$ & Gamma & Gamma \\
\hline QUATER10 & $\mathrm{HE}$ - PAH & Sandwich Herringbone & Sandwich Herringbone \\
\hline RADSOF & $\mathrm{HE}-\mathrm{PAH}$ & Gamma & Gamma \\
\hline SEDTUQ & $\mathrm{HE}-\mathrm{PAH}$ & Sandwich Herringbone & Gamma \\
\hline SURTAA & $\mathrm{HE}-\mathrm{PAH}$ & Gamma & Gamma \\
\hline TBZHCE & $\mathrm{HE}-\mathrm{PAH}$ & Gamma & Gamma \\
\hline TBZPER & $\mathrm{HE}-\mathrm{PAH}$ & Beta & Beta \\
\hline TBZPYR & $\mathrm{HE}-\mathrm{PAH}$ & Gamma & Gamma \\
\hline TETCEN01 & $\mathrm{HE}-\mathrm{PAH}$ & Herringbone & Herringbone \\
\hline TIBMIA & $\mathrm{HE}-\mathrm{PAH}$ & Beta & Beta \\
\hline TIBMIA01 & $\mathrm{HE}$ - PAH & Beta & Beta \\
\hline TNBENZ10 & $\mathrm{HE}-\mathrm{PAH}$ & Gamma & Herringbone \\
\hline TNBENZ11 & $\mathrm{HE}$ - PAH & Gamma & Sandwich Herringbone \\
\hline TNBENZ12 & $\mathrm{HE}-\mathrm{PAH}$ & Herringbone & Herringbone \\
\hline TNBENZ13 & $\mathrm{HE}-\mathrm{PAH}$ & Gamma & Gamma \\
\hline TNIOAN01 & $\mathrm{HE}-\mathrm{PAH}$ & Gamma & Herringbone \\
\hline TNIOAN02 & $\mathrm{HE}$ - PAH & Gamma & Sandwich Herringbone \\
\hline TRIPHE11 & $\mathrm{HE}-\mathrm{PAH}$ & Gamma & Gamma \\
\hline VEBJAO & $\mathrm{HE}-\mathrm{PAH}$ & Gamma & Gamma \\
\hline VEBJES & $\mathrm{HE}-\mathrm{PAH}$ & Gamma & Gamma \\
\hline VEHCAM & $\mathrm{HE}-\mathrm{PAH}$ & $\mathrm{N} / \mathrm{A}$ & $\mathrm{N} / \mathrm{A}$ \\
\hline VENCEZ & $\mathrm{HE}$ - PAH & Gamma & Gamma \\
\hline VUFHUA & $\mathrm{HE}$ - PAH & Beta & Beta \\
\hline XATZUO & $\mathrm{HE}-\mathrm{PAH}$ & Beta & Beta \\
\hline XUDREV & $\mathrm{HE}-\mathrm{PAH}$ & Gamma & Gamma \\
\hline YAPVAM & $\mathrm{HE}-\mathrm{PAH}$ & N/A & N/A \\
\hline YEHDOF & $\mathrm{HE}-\mathrm{PAH}$ & Beta & Beta \\
\hline YEKQAG & $\mathrm{HE}-\mathrm{PAH}$ & Gamma & Gamma \\
\hline YEKQAG01 & $\mathrm{HE}-\mathrm{PAH}$ & Gamma & Gamma \\
\hline YEKQAG03 & $\mathrm{HE}$ - PAH & Gamma & Gamma \\
\hline YIKSEQ & $\mathrm{HE}$ - PAH & Gamma & Gamma \\
\hline YITJAN & $\mathrm{HE}-\mathrm{PAH}$ & Gamma & Herringbone \\
\hline YOFCUR & $\mathrm{HE}-\mathrm{PAH}$ & Gamma & Gamma \\
\hline YOHDUW & $\mathrm{HE}-\mathrm{PAH}$ & Gamma & Gamma \\
\hline YOMYII & $\mathrm{HE}-\mathrm{PAH}$ & Sandwich Herringbone & Sandwich Herringbone \\
\hline YUXHAB & $\mathrm{HE}$ - PAH & Gamma & Gamma \\
\hline ZADVIM & $\mathrm{HE}-\mathrm{PAH}$ & $\mathrm{N} / \mathrm{A}$ & $\mathrm{N} / \mathrm{A}$ \\
\hline ZAYWAX & $\mathrm{HE}-\mathrm{PAH}$ & Gamma & Gamma \\
\hline
\end{tabular}




\begin{tabular}{|c|c|c|c|}
\hline ZEHDAT & $\mathrm{HE}-\mathrm{PAH}$ & N/A & N/A \\
\hline ZEYROM & $\mathrm{HE}-\mathrm{PAH}$ & N/A & N/A \\
\hline ZOFTAP & $\mathrm{HE}-\mathrm{PAH}$ & Gamma & Gamma \\
\hline ZONJUH & $\mathrm{HE}-\mathrm{PAH}$ & Beta & Beta \\
\hline ZORJOF & $\mathrm{HE}-\mathrm{PAH}$ & Beta & Beta \\
\hline zOWSUZ & $\mathrm{HE}-\mathrm{PAH}$ & Gamma & Gamma \\
\hline ZUGPOG & $\mathrm{HE}-\mathrm{PAH}$ & Gamma & Gamma \\
\hline ZUHRID & $\mathrm{HE}$ - PAH & Gamma & Gamma \\
\hline ZUNPOP & $\mathrm{HE}-\mathrm{PAH}$ & Beta & Beta \\
\hline ZZZOYC01 & $\mathrm{HE}$ - PAH & Herringbone & Herringbone \\
\hline BAKLII & Review & Gamma & Gamma \\
\hline BINSAS & Review & Herringbone & Herringbone \\
\hline BZOFOX & Review & Herringbone & Gamma \\
\hline CLNOBE02 & Review & Gamma & Gamma \\
\hline CTMTNA & Review & Gamma & Gamma \\
\hline DAFPUV & Review & Gamma & Gamma \\
\hline DATNBZ01 & Review & Gamma & Gamma \\
\hline DNBZFX & Review & $\mathrm{N} / \mathrm{A}$ & $\mathrm{N} / \mathrm{A}$ \\
\hline DOYCID & Review & N/A & N/A \\
\hline EWUKIQ & Review & Herringbone & Herringbone \\
\hline GEMZAZ & Review & Beta & Beta \\
\hline GETFIU01 & Review & Gamma & Gamma \\
\hline GIMBOT & Review & Gamma & Gamma \\
\hline GIZPOX & Review & Sandwich Herringbone & Herringbone \\
\hline HEXTIN & Review & Beta & Beta \\
\hline HNIDPA01 & Review & Gamma & Gamma \\
\hline HNOBEN & Review & Beta & Beta \\
\hline KAVFUI & Review & Gamma & Gamma \\
\hline MTNANL & Review & Herringbone & Herringbone \\
\hline NABMAE & Review & N/A & N/A \\
\hline NABMOS & Review & Gamma & Gamma \\
\hline PABBOJ & Review & Gamma & Sandwich Herringbone \\
\hline PIGSOP & Review & Sandwich Herringbone & Sandwich Herringbone \\
\hline SAWBUN & Review & Gamma & Herringbone \\
\hline TATNBZ & Review & Beta & Beta \\
\hline TEVHEH & Review & Herringbone & Herringbone \\
\hline TICYOT & Review & Herringbone & Herringbone \\
\hline TNIOAN & Review & Gamma & Gamma \\
\hline TNITAN & Review & Sandwich Herringbone & Sandwich Herringbone \\
\hline TNOXYL & Review & Gamma & Gamma \\
\hline TNPHNT & Review & Gamma & Gamma \\
\hline WEKGUP & Review & Gamma & Herringbone \\
\hline XACCUC & Review & Gamma & Gamma \\
\hline YAHJIB & Review & N/A & N/A \\
\hline YAHJOH & Review & Beta & Beta \\
\hline YAHKID & Review & $\mathrm{N} / \mathrm{A}$ & N/A \\
\hline ZZZMUC01 & Review & Gamma & Gamma \\
\hline
\end{tabular}

\section{Evaluation parameters}

At several places in the Autopack code there are parameters that can be tuned based on the needs of the use case. These are expressed through a JSON file read in during the program's execution. We provide a set of parameters that works well for us as default. The parameters are as follows: 
- Threshold: The number of molecules to expand in the crystal structure during optimization. Larger thresholds will generally take longer but better estimate the correct motif plane. (Default 120)

- Restarts: The number of times to restart the optimization process due to local minima. Further explained in the Optimization landscape section below. (Default 4)

- In plane: The degree cutoff for two planes to be considered parallel or non-parallel. This is set by manually labeling a handful of beta and gamma crystal structures and determining an empirical cutoff between the two. (Default 25)

- Alpha: The constant multiplier for the height of the boundary disk of the motif plane empirically set. Default (1.2)

- Z_penalty: When sampling neighbors within the disk around the motif plane, there is a tradeoff between choosing neighbors that are closer to the motif plane and choosing neighbors which are closer to the reference molecule. This penalty acts as a way to bias neighbor choice towards molecules that are closer to the motif plane rather than Euclidean distance to the reference molecule and is empirically set. (Default 0.03)

\section{OPTIMIZATION}

\section{Optimization landscape}

In order to solve for $\theta$ and $\phi$, the rotation angles which minimize the projected area of the molecules within a crystal structure, we employ the use of gradient descent. One problem with gradient methods are their susceptibility to both local minima and plateaus within an optimization landscape leading to poor convergence. We demonstrate the reality of this problem in Fig. S1a where molecule Dinaphtho(1,2-a:1',2'-h)anthracene [1] has multiple plateaus as seen by the two bands found near $\theta=90^{\circ}$ and $\theta=270^{\circ}$. The first step to remedy this issue is to remove redundancy within the parameter space as $180^{\circ}$ rotations of the crystal structure produce the same final structure except mirrored. By reducing the possible values of both $\theta$ and $\phi$ 's to between $0^{\circ}$ and $180^{\circ}$, the plateau at $\theta=$ $270^{\circ}$ is removed. Despite this constraint, there is still the possibility of getting stuck in the plateau at $\theta=90^{\circ}$ depending on initialization as seen in Fig. S1b. To fix this problem, we utilize a line search through the parameter space searching for the optimal initialization and global minima based on the number of restarts chosen. We calculate the initialization points at a given restart to be:

$$
\theta_{\text {init }}=\phi_{\text {init }}=I *\left(\frac{180^{\circ}}{R+1}\right)
$$

where $R$ is the number of total restarts and $I$ is the current restart iteration from 0 to $R$, which produces a diagonal line through the parameter space. The optimal $\theta$ and $\phi$ are found by taking the $\theta_{\text {init }}$ and $\phi_{\text {init }}$ which produce the minimum projected area.

a)

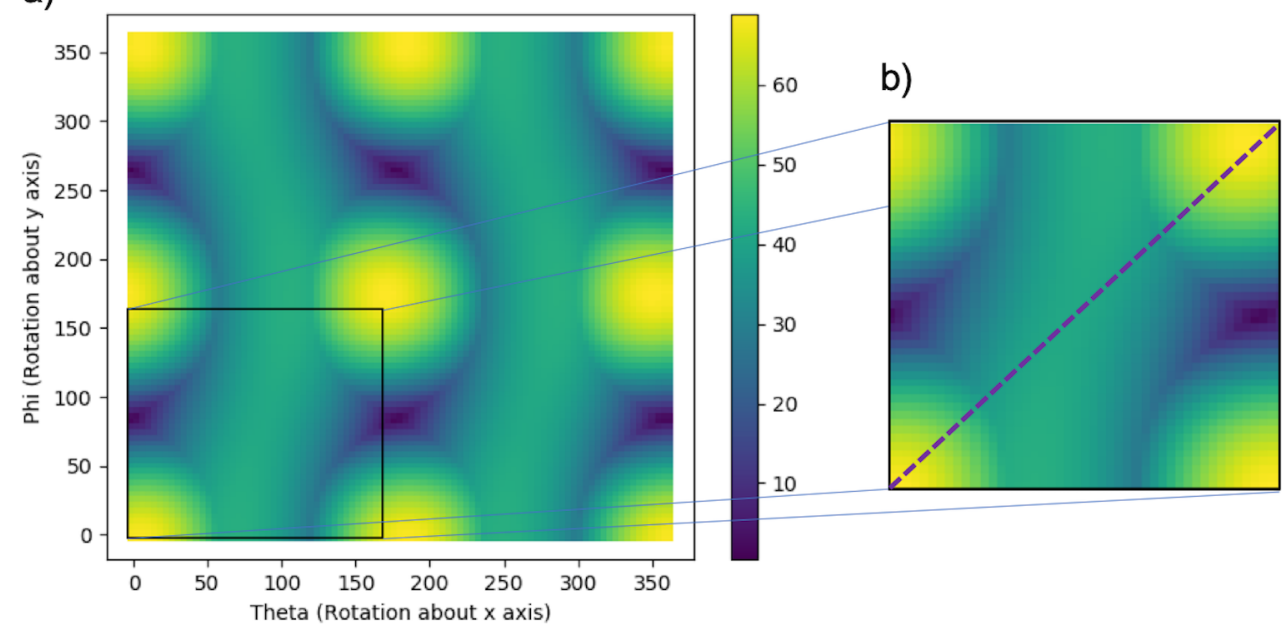

Figure S1. Optimization landscape for Dinaphtho(1,2-a:1',2'-h)anthracene (CSD identifier DNAPAN) [1]. Colors represent the projected area on X-Y axis, where purple is lower area and yellow is higher area. In the case of optimization, we are interested in lower area, thus the dark purple regions. Generally speaking, all of the dark purple areas are of equal quality. a) Entire optimization landscape with $360^{\circ}$ rotations about each axis. b) Focused optimization landscape with $180^{\circ}$ rotations. The purple diagonal dashed line represents the possible initialization locations generated from equation S1. 


\section{REFERENCES}

[1] Hummelink-Peters, B. G. M. C.; Hark, T. D.; Noordik, J. H.; Beurskens, P.T. Cryst. Struct. Comm., vol. 4, p. 281, 1975. 